\title{
Demand and Guarantee of Internet Use for Physically Disabled Children in Wenchuan Earthquake
}

\author{
Jianghua Luo ${ }^{1}$, Huifen Guo ${ }^{1} \&$ Jue Wang ${ }^{1}$ \\ ${ }^{1}$ College of Center for Studies of Education and Psychology of Ethnic Minorities in Southwest China, Southwest \\ University, Chongqing, China \\ Correspondence: Jianghua Luo, College of Center for Studies of Education and Psychology of Ethnic Minorities \\ in Southwest China, Southwest University, 2 TianSheng Road, Chongqing 400715, China. E-mail: \\ swusun@swu.edu.cn
}

Received: November 24, $2012 \quad$ Accepted: January 5, $2013 \quad$ Online Published: February 28, 2013
$\begin{aligned} & \text { doi:10.5539/ass.v9n3p112 } \\ & \text { URL: http://dx.doi.org/10.5539/ass.v9n3p112 }\end{aligned}$

The study is supported by the Fund of the Key Topic 2010 of Ministry of Education in National Educational Science "Eleventh Five-year" Plan. Study on Supports for Digitized Learning of Disabled Children in Wenchuan Earthquake. [DCA100201] And the study is also supported by the Fund of the Project of Key Research Institute of Humanities and Social Science of Chongqing City. Study on the Impacts of Modern Media on Socialization of Children in Mother Tongue Areas. [11SKB19]

\begin{abstract}
Most of physically disabled children in Wenchuan Earthquake in 2008 had strong demand for internet use to obtain information on daily rehabilitation, expand interpersonal relationship and support schoolwork progress, so "Digital Campus" built after disaster provided the environment for internet use. Nevertheless, parents and teachers had disagreements regarding physically disabled children's independent internet use. To guide physically disabled children's reasonable use of internet, it is necessary to form a collaboration mechanism of government, community, school and family, develop "applicable" resources and focus on improving physically disabled children's capability of information identification.
\end{abstract}

Keywords: internet, demand for use, physically disabled children

\section{Research Topic}

According to the report of Sichuan Provincial Government on rebuilding after Wenchuan Earthquake on May 7 , 2009, earthquake-stricken areas had identified and issued disability certificate to around 550 disabled children. Disabled children in Wenchuan Earthquake suffered from damaged limbs and spine fractures. (He Chengqi: 2008) Thus, attention should be paid to these children in the rebuilding of education system after disaster.

Governments tracked and recorded the physical and psychological development of disabled children in the earthquake through database and quickly completed the schools suitable for disabled children. For some children that were severely disabled and incapable to receive school education, governments arranged volunteers to provide household tutoring at first. After school buildings were basically completed, governments advocated to assist the study and life of disabled children by means of internet, and included pertinent measures into the "Twelfth Five-year Development Plan for Disabled People".

Academically, Chinese scholars propose integration of information technology and courses and improvement of teachers' information knowledge in the research on disabled children's internet use, (Zhou Huiyin \& Chen Lin: 2009) particularly focus on the opportunities for disabled children to use internet and advocate the establishment of information resource platform for disabled children. (Zheng Quan: 2010) The researches in China have demonstrated that disabled children in Wenchuan Earthquake are subject to different cycles of education due to different ages no matter whether they are educated at school or at home, and that their schoolwork is also affected by long-time rehabilitation training to some extent. (Luo Jianghua \& Deng Xiaohua: 2010) As they are physically disabled unexpectedly, some children become sensitive and feel lonely. Moreover, $30-40 \%$ of children suffer from different degrees of troubles in obtaining information resources. (Hua Dong \& Shen Wenwei: 2011)

Most of physically disabled children in Wenchuan Earthquake come from the mountainous areas in the valleys of 
Minjiang River, Peijiang River and Bailongjiang River, where were not entirely accessible to internet due to backward economy and isolation before the earthquake. A lot of families with physically disabled children are poverty-stricken, so parents go to other places for work and arrange their children to stay with grandparents or relatives. After the earthquake, there appear some new issues. Thanks to national school rebuilding plan, schools and rural communities have obtained all necessities for access to internet, such as, computers, software, long-distance shared courseware, etc. However, attention must be urgently paid to whether physically disabled children have the same demand, preference and capability for internet use as normal children, what they mainly use internet to do, what roles teachers or parents should play, and what arrangements schools must make to help them. It's urgent to pay attention to these actual events and the hidden educational problems.

\section{Research Methodology}

\subsection{Procedure of the Fieldwork}

For this research, we surveyed D City in middle May and the third week of November, 2010, and late October, 2012. D City situated next to a metropolis, so it was well developed economically and very modern. Before the earthquake, it already had a high coverage of internet. In the survey, we selected Y School special for physically disabled children for questionnaire survey and participant observation.

Q County situated in a remote mountainous area away from the metropolis. It was very severely affected by the earthquake in 2008. On May 7-20, 2011 and November 8-19, 2011, we surveyed and interviewed some physically disabled children at 34 primary and middle schools in Q County.

\subsection{Respondents of the Fieldwork}

Y School in D City particularly accepted physically disabled children in Wenchuan Earthquake throughout Sichuan Province. According to Y School's register of students with disabilities in 2010, there were 113 students with disabilities. $64 \%$ of these students were girls and $65 \%$ were from poverty-stricken families. $73 \%$ of these students came from severely stricken areas, including 16 children from Q County. Among them, 2\% suffered from first and second degrees of disability (i.e. severe disability), while $65 \%$ have third and higher degrees of disability (i.e. slight disability). In September 2011, the number of physically disabled children in Wenchuan Earthquake went to Y School reached 121, but the aforesaid percentages did not change.

Y School provided nine-year compulsory education with accessibility design and accepted both disabled and normal children. Normal children came from the local city-D City while physically disabled children were from remote villages and different nationalities, such as, Han, Qiang, Tibetan and Hui, etc. The school classed and grouped physically disabled children with normal children, but arranged the daily life of physically disabled children in a unified manner and established special office, infirmary, psychological health office and nursing \& rehabilitation office for them.

In this research, we particularly observed 68 physically disabled children at 34 local schools in Q County. Like Y School in D City, these children mainly had slight disability, but most of them came from extremely poverty-stricken families. Among these children, $53 \%$ were girls and $81 \%$ came from poverty-stricken families. Moreover, $10 \%$ of these children had difficulties in going to school due to physical disabilities.

In this aspect, Q County had three special features. 1. Some physically disabled children had not received disability certificate due to complex procedure of disability evaluation or lack of relevant information; and their slight disability became severe as they missed the optimal time of treatment. 2. Physically disabled children in Q County were distributed at 34 schools without accessibility facilities or boarding service.

\subsection{Themes of the Fieldwork}

Questionnaire survey has three themes. 1. The internet accessibility of new schools after rebuilding, particularly, computer configuration, internet bandwidth and software. 2. Physically disabled children's capability of internet use. 3. Physically disabled children's attitude, frequency and purpose of internet use, and influence of internet on interpersonal relationship and schoolwork development.

Interview and observation is intended to describe the influence of internet on the schoolwork and social affection of physically disabled children in the earthquake. It mainly involves the following aspects: 1 . Observe the relationships among supervisors, teachers, children and guardians and have field trips to check the environment for children's internet use and obtain relevant information. 2. Select some children and observe them based on age, gender and capability, and keep contact with them to record relevant information upon their consent.

\section{Analysis and Viewpoint}

Sichuan Province was most severely affected by Wenchuan Earthquake, so it received great aids from developed 
regions in East China to quickly step into the information age featured by accessibility and use of internet. As revealed in the Internet Development Report 2011 of Sichuan Province, the coverage of internet increased very rapidly, up 5.5\% in 2011, ranking in the top list in China. The netizens in Sichuan Province became younger and younger, and $39.4 \%$ of them were 19 years old and younger, $11 \%$ higher than the national's average level.

At the schools and villages we surveyed in D City and Q County, internet has gradually entered backward villages. Thus, governments expanded their preferential policies to less educated people and focused on disabled people's demand for internet. It's obvious that the physically disabled children can use internet more and more conveniently, and the number of these users is increasing constantly.

\subsection{Diversified Demands}

\subsubsection{Spreading the Service of "Online Diagnosis"}

In this research, physically disabled children did not have severe disability. Some of them were amputated and had to depend on wheelchair, crutches or artificial limbs, but still had two hands. Some of them might have injured hands, but not amputate their hands, so they could still take care of themselves, write and use computer and did not require special hardware support to use computer.

Nevertheless, physically disabled children lacked the knowledge of rehabilitation, so they urgently needed daily training for rehabilitation and follow-up service. In early 2012, Y School in D City planned to build a rehabilitation training room of more than 200 square meters in its unoccupied space (with the donation of Chengdu Charity Federation). Before this project was completed, the rehabilitation training for more than 100 physically disabled children in the earthquake was always a troublesome issue, and most of physically disabled children did not have accurate information to support their follow-up rehabilitation.

In Q County, physically disabled children did not receive any special examination or service in the past three years. As revealed in the survey, $74 \%$ of children did not receive rehabilitation examination since free medical aid was over and $82 \%$ of children did not know how to do regular rehabilitation training. In 2009, Sichuan Provincial Government released a special care policy to cover the expenses of follow-up medical rehabilitation and medical treatment for enrolled students identified to have the first to fourth degrees of disability as well as their families. However, only a few parents of physically disabled children knew about this policy. Subject to limited information channel, most of physically disabled children missed the critical period of rehabilitation treatment.

At present, the service of "Online Diagnosis" is urgently needed for physically disabled children, Moreover, the densely distributed internet facilities at the communities and schools in the earthquake-stricken areas and the village-level health information projects are also urgently needed to establish the information files of physically disabled children in the earthquake, in order to guarantee that physically disabled children can timely obtain the information on policies and high-quality medical resources can be sent into remote mountainous areas. In this way, a communication channel could be constructed.

\subsubsection{Expanding Interpersonal Connection through Internet}

Psychological rehabilitation of physically disabled children in Wenchuan Earthquake is a long process, but it is obviously difficult to provide long-time face-to-face consulting service due to limited time, energy and fund. Some caring people initiated an activity called "Online Interaction" to offer the psychological aid to physically disabled children in Wenchuan Earthquake, which achieved good effect. For instance, a group of volunteers with disabilities from Hunan Province built frequent online connections with 320 disabled people from the stricken areas in Sichuan, in order to help each other through internet. The caring people from Shandong Province initiated the "Q County Disabled Adolescents Care Program" to provide services for new physically disabled children in Q County. By resorting to online chatting platform, they help physically disabled children eliminate psychological shadows and adjust to new life.

Physically disabled children in Wenchuan Earthquake had a strong desire of online chatting platform. As they were traumatized by the earthquake physically and psychologically, disabled children might easily get along with each other and be glad to hang out with each other due to similar experience. Taking the data of survey in Q County as example, when physically disabled children stayed with normal children, $70.5 \%$ easily became irritable and self-abased; $57 \%$ believed that they were "uncommunicative"; and $91 \%$ thought it difficult for themselves to communicate with normal children. Actually, this was mainly caused by inferiority complex due to physical inconvenience and dependent living.

In the survey with the theme of "Internet Use", it was discovered that physically disabled children were very interested in internet use. Among them, $98.5 \%$ wished to communicate through internet and $29.4 \%$ had already 
used the internet, of which $80 \%$ believed that internet could help them effectively and $90 \%$ believed that they could find the resources for learning through internet.

\subsubsection{Satisfying the Demand for Schoolwork Development through Internet}

In regular class, learning level was quite different between physically disabled children and normal students. Among 113 physically disabled students in regular classes at Y School in D City, 89\% came from the rural areas in neighboring counties with a learning base lower than normal students from urban areas; and $49.5 \%$ believed that their learning level decreased after the earthquake. Y School in D City once arranged teachers and volunteers to provide "one-to-one" tutorship for physically disabled students, and achieved good effect. However, teachers did not have enough time and volunteers could not provide face-to-face tutorship frequently. Now, the "one-to-one" tutorship has been basically cancelled.

Physically disabled students had already shown their job tendency when they entered middle school, but there was not sufficient vocational education. As revealed in the survey, $55 \%$ of children expressed that they were more willing to receive vocational education earlier, in order to get a job more easily when they grew up. Nevertheless, Y School in D City and regular primary and middle schools in Q County did not provide the training of daily living skills and vocational skills for physically disabled children. In addition, they still provided courses focusing on academic knowledge and skills and did not have teachers or resources for the courses of vocational training.

More and more physically disabled children chose to stay at home. As revealed in the survey on rural areas in Q County, some physically disabled children missed the critical period of rehabilitation treatment, so they suffered from physical disabilities. Moreover, schools in rural areas could not provide accommodation for these children, so they had to be only homeschooled. In addition, some physically disabled children became "apprenticed" to shoemakers, embroiderers, tailors and other handicraftsmen in rural areas after completing their study in primary school, so they had to stay at home.

Thus, all kinds of learning resources on the internet must be utilized for self-adjusted and independent learning of physically disabled children. Online learning has its unique advantages. For physically disabled children, the first advantage is "convenience". By means of internet, physically disabled children can communicate with other people "face to face" at home, and effectively contact their teachers and friends. The other advantage is to provide more tools for online teaching and make it possible to arrange personalized and tailored teaching for physically disabled children in the earthquake. In this survey, 34 primary and middle schools had computer classroom with internet access, and there were internet bars in the villages where schools located.

\section{2 "Hardware" and "Software" Conditions}

As the "Digital Campus" project for schools in stricken areas was completed, hardware and software conditions had been achieved for internet use. Through the plan of "Digital City", D City had basically integrated the extension, sharing and service of urban and rural information resources, and given prominence to the characteristics of "Network in Urban and Rural Areas". Most of internet access facilities at Y School in D City were donated by other parties, so they had good performance and different types. With external aids, Q County worked hard to build the e-commerce of agricultural products and increase the information knowledge of younger generation, and expected that young people could make good use of internet to propagandize local ecological agriculture and cultural tourism. Moreover, it took this as a new point of economic growth. Thus, Q County attempted to integrate education, health and administrative resources on the unified information platform. In this survey, 34 primary and middle schools had computer classroom with internet access, and there were internet bars in the villages where schools located.

At the primary and middle schools in D City and Q County, more and more teachers used electronic touch screens in teaching classes, so the era of "chalk + blackboard" was completely over. At Y School in D City, every physically disabled student had a learning device for digital reading and online browsing. Moreover, the school had two computer rooms and many multimedia classrooms. In Q County, the primary and middle schools in rural areas opened the live classes for remote online teaching from sponsors in the "Digital Q County" program, in order to realize educational supports for these schools.

In the rebuilding after disaster, rural health information infrastructures developed rapidly in the earthquake-stricken areas. Since 2009, Health Department of Sichuan Province had firmly pushed forward rural medical health information projects, speeded up the process of health service informationization in rural communities, and particularly established health service information management platform in county-level and village-level communities. D City, Q County and other regions started providing internet facilities for 
county-level hospitals and village-level clinics and utilized rural health service management software to eliminate the difficulties in monitoring and treating the health problems of key groups, including old people and children. By 2010, the "TelePresence System" donated by Cisco Systems Inc. had connected some community health systems in the levels of county, township and village. Therefore, rural communities could realize "Online Diagnosis". According to design objectives, physically disabled children in the earthquake could enjoy remote medical service by means of online appointment and "Online Diagnosis" system could give rehabilitation advices to them.

\subsection{Trepidation of Parents and Teachers}

Why is online teaching needed? Will it affect the healthy growth of physically disabled children if they have access to internet for a long time? In every school we visited, there were always some teachers who asked these questions. This controversy related to two issues. Firstly, the test papers, courseware, textbooks and teaching plans presented for teaching on the internet could not arouse physically disabled children's interest in learning. Most of online curriculums from famous schools focused on exam-oriented education, so they were not suitable for the learning of physically disabled children. Secondly, most of parents were not willing to expose young children to internet for some reasons, mainly including "myopia, addiction to playing games, porn, scam", etc.

How is the effect of online teaching? Some schools made use of "TelePresence System" built with one-to-one aid to create the environment of remote, real-time and interactive communications. Thus, students in the earthquake-stricken areas and students in Shanghai could take a class together. Moreover, they might use online videos to realize the sharing and utilization of teaching resources in classrooms. However, online teaching was considered as a "show" and waste of time in the practical operation, as it did not match with the teaching process of schools in the earthquake-stricken areas and remotely transmitted teaching videos were not well focused.

At Y School in D City, disabled and normal students stayed together in classes, so physically disabled children did not have much time for their independent learning and were required to "study the same subjects and take examinations according to the same curriculum" like normal children. Teachers needed to spend almost all of their time in preparing for and teaching classes and grading homework, and grades in examinations were still the major criteria for evaluation. Guiding physically disabled children's internet use was considered as an exclusive duty of information technology teachers, so "network-based regular learning" had not taken shape yet.

In Q County, some schools opened "Internet Use Experimental Class", and even established online learning assistance group for physically disabled children, but students could not have access to computer conveniently, let alone unlimited internet use. At some schools, physically disabled children might only use internet in computer room at the time of extracurricular activity in the afternoon or at weekends. Some physically disabled children and their friends thought it boring to use internet at school, so they often went to internet bars at weekends and hung out with young loafers, which parents were quite concerned about.

\subsection{Differences in Motives and Effects of Internet Use}

The survey data reveal that primary and middle schools in D City and Q County have opened the course of information technology, and most of physically disabled children in the earthquake are able to smoothly acquire information on the internet based on the needs in their learning.

Y School in D City had two specialized computer rooms for teaching, and electronic whiteboards in classrooms had been connected to internet. The theme trainings including electronic whiteboard, multimedia application and courseware preparation had become the important contents in the vocational learning of teachers for the past two years. Among physically disabled children in the earthquake at Y School in D City, $85 \%$ had proficiently used internet to search for information and resources. The survey on the rural schools in Q County showed that physically disabled children became more and more willing to acquire information. Among the physically disabled children who never used computer before the earthquake, $53 \%$ had mastered the basic knowledge in the information technology classes, $37 \%$ had learned how to use Baidu.com and other search engines, $85 \%$ had used QQ for communications with others and 7\% had even registered their own blogs.

As shown in the analysis on the "Internet Use Journal" of three students (The Table Below), we will notice some obvious problems in the purpose, way and habit of physically disabled children's internet use.

As more and more teachers and parents "interfere", children's internet use become more and more reasonable. For instance, Student A lived with her parents (school teachers), owned a personal computer and was supported by parents to use internet, so she often read online news, wrote blogs, searched for materials and studied how to play the erhu (a two-stringed bowed musical instrument) on the internet. However, only $10 \%$ of physically disabled children in the earthquake lived with their parents and were looked after by their parents in the survey. 
Student B chose to board at school as his home was far away from the school, so he could use internet in the school's computer room in the class of information technology and at the time of extracurricular activity in the afternoon. The duration of internet use was controlled by teacher, so his internet use was basically reasonable. These children took up around $13 \%$ of total respondents in the survey.

Most of physically disabled children also had a broken home and most of their relatives worked in other cities. As rural schools were surrounded by internet bars and physically disabled children could not do sports, so they preferred to use internet and it was very common to see physically disabled children addict to online games. For instance, Student $\mathrm{C}$ lost his father in the earthquake and his mother and old sister left for work in other cities. He was introverted and liked to be alone. He liked online games and became addicted to internet. Actually, $40 \%$ of respondents in the survey in Q County were similar to this student.

Table1. Records of physically disabled children's internet use

\begin{tabular}{|c|c|c|}
\hline Respondent & Basic Information & Behavior Description \\
\hline Student A & $\begin{array}{l}\text { Girl, } 15 \text { years old, Grade } 3 \text { in junior } \\
\text { middle school, 17:30 to 18:40 Tuesday } \\
\text { afternoon. (live with parents, often use } \\
\text { the internet at home and use the internet } \\
\text { at the computer room of school in the } \\
\text { class of information technology, extern } \\
\text { student. Duration of internet use is around } \\
7 \text { hours every week.) }\end{array}$ & $\begin{array}{l}\text { Use the internet at home. } 1 \text {. Browse } 163 . \mathrm{com} \text {, for } 15 \\
\text { minutes. 2. Search for information on vocational } \\
\text { school on Baidu.com, for } 22 \text { minutes. } 3 \text {. Log in QQ } \\
\text { and chat with friends, which lasts during the whole } \\
\text { period of internet use for unclear purpose. } 4 \text {. Write an } \\
\text { email to contact with sponsor, report the latest } \\
\text { problems of artificial limb (left leg) and ask for his } \\
\text { help to contact the manufacturer for treatment. }\end{array}$ \\
\hline Student B & $\begin{array}{l}\text { Boy, } 12 \text { years old, Grade } 5 \text { in primary } \\
\text { school, 11:20 to 12:00 Wednesday } \\
\text { morning. (use the internet only at school } \\
\text { and board at school. Duration of internet } \\
\text { use is around } 3 \text { hours every week.) }\end{array}$ & $\begin{array}{l}\text { Use the internet at the computer room of school. } 1 . \\
\text { Complete the task assigned by teacher, use WORD to } \\
\text { establish "Personal File", communicate with } \\
\text { classmates and submit the result to teacher for } \\
\text { inspection. The process lasts for } 21 \text { minutes. } 2 \text {. Log } \\
\text { in QQ and QQ pet, and chat with QQ friends (mainly } \\
\text { related to the game "Seer"). The process lasts for } 12 \\
\text { minutes. 3. Listen to the teacher in the remaining } \\
\text { time. }\end{array}$ \\
\hline Student C & $\begin{array}{l}\text { Boy, } 15 \text { years old, Grade } 2 \text { in junior } \\
\text { middle school, 10:35 to } 13: 36 \text { Sunday } \\
\text { afternoon. (often use the internet at the } \\
\text { computer room of school and internet bar } \\
\text { and board at school. Duration of internet } \\
\text { use is around } 7 \text { hours every week.) }\end{array}$ & $\begin{array}{l}\text { Use the internet at internet bar. } 1 \text {. Log in QQ to chat } \\
\text { with his sister working in Dongguan ( } 19 \text { years old, } \\
\text { graduate from vocational high school, work in } \\
\text { e-commerce), for } 55 \text { minutes. 2. Play a game called } \\
\text { "Glories of Three Kingdoms", for } 125 \text { minutes, } \\
\text { without any interruption. }\end{array}$ \\
\hline
\end{tabular}

\section{Conclusion and Recommendations}

\subsection{Conclusion}

As revealed in the analysis of survey data, physically disabled children in Wenchuan Earthquake have the demand for internet use in three aspects: 1. As physically disabled children are growing up, follow-up rehabilitation treatment and replacement of artificial limbs must match with their growth, and information should be timely and accurately provided for them through "Online Diagnosis" system in the earthquake-stricken areas. 2. Unexpected physical disabilities make physically disabled children feel isolated and depressed, so internet must be utilized to expand their interpersonal space. 3. Physically disabled children may be easily anxious about schoolwork since they often miss classes for receiving treatments. Thus, internet must be employed to help them arrange the time and schedule of study independently.

In respect to the environment of internet use, physically disabled children are arranged in regular classes, but $\mathrm{Y}$ School is equipped with accessibility facilities, rehabilitation and psychological counseling offices, professional life management teacher and information technology teacher, etc., which are not provided at primary and middle schools in Q County. Physically disabled children in Q County still live in the original "Cultural Circle", but they lack the love of family as their parents work in other cities. A lot of physically disabled children board at schools, 
but they cannot receive continuous care and life assistance as there are too many students and teachers are overburdened by work, etc. Thus, it is easily noticed that: 1 . When the conditions for internet use are the same, physically disabled children without love and care from family and teachers have a stronger desire of internet use and are more easily addicted to internet since they mainly use internet for making friends and playing games. 2 . The model of Y School is more helpful to guiding physically disabled children's reasonable use of internet. 3. The use of internet may not always encourage physically disabled children to develop a positive and practical attitude, so we should design focused courses, special online resources and software to protect children against unhealthy information while keeping in mind that internet can bring convenience to them. 4 . In the virtual space of internet, physically disabled children should still keep self-respect and remember their roles in family, school and community, which is very important for them to use internet to cope with disabilities, understand the outside world and be independent.

\subsection{Recommendations}

To guide the reasonable internet use of physically disabled children in the earthquake, government, society, school and family are required to cooperate with each other to develop "applicable" resources, promote mobile learning equipment, prevent negative effect of internet world on physically disabled children in the earthquake, protectively expand the environment for socialization of physically disabled children, and guide them in the personalized learning.

\subsubsection{Constructing a Practical and Effective Mechanism through Cooperation among Many Parties}

When internet is used to improve the conditions of living and learning for physically disabled children in the earthquake, it is necessary to strengthen the idea of "all for the future of physically disabled children in the earthquake" and form a cooperating mechanism responsible by governments, implemented by schools and communities and supervised by families, in order to guide physically disabled children in the earthquake to use internet reasonably.

Governments should consider the physical and psychological characteristics of physically disabled children in the earthquake, well perform the planning and construction of infrastructures, and satisfy physically disabled children's needs of online communication and learning. Infrastructures are the premise for personalized learning, so it is necessary to make efforts to gain a good-quality handheld learning terminal with complete functions for every physically disabled child. Utilize "three-level network health information platform" to establish the normal mechanism of tracking physically disabled children in the earthquake. Distribute the responsibility of guiding physically disabled children in the earthquake in online learning to schools and communities in the "Digital Campus" project.

Schools should try the task-based teaching method, utilize the course of information technology, carry out exploratory learning, and give specific task requirements to physically disabled children, in order to strengthen their awareness of using information technology as a tool reasonably. After that, information technology can be used as a tool to monitor and properly interfere with the conditions of living and learning of physically disabled children in the earthquake, and guide them to combine "online communication" and "actual life". With the help of internet, schools should consciously make physically disabled children and normal children form learning groups and advocate their cooperation, in order to nurture physically disabled children's good adaptability to the society.

Society should make use of internet to build a support and guarantee team for physically disabled children in the earthquake. "Volunteers" can be recruited through internet. While recruiting volunteers, it is necessary to consider the structure of their profession, accept more persons with multidisciplinary education as volunteers, and guide the collaboration of volunteers. "Volunteers" can provide the all-directional supports for physically disabled children not only in their learning of knowledge and but also in their psychological development and life experience.

Families should create an atmosphere for reasonable internet use. It has been proved that family plays a more important role in physical and psychological rehabilitation of disabled people in the earthquake. In the process of children's internet use, their guardians must be also the best guides. Guardians must well guide children by means of "devotion, game, autonomy". "Devotion" means that physically disabled children are required to devote themselves to learning during internet use, so as to prevent distraction by mass information on the internet. "Game" underscores that game is properly combined with learning to make physically disabled children feel that learning is an easy and happy process. "Autonomy" means that guardians should pay enough attention to physically disabled children and give sufficient autonomy to children in their activities, in order to motivate them in further learning. (Stoney, S. \& Oliver R.: 1998) 


\subsubsection{Developing "Applicable” Resources and Constructing Information Sharing Channel}

With regard to "hardware", "handheld" terminal should be a practical choice for physically disabled children in the earthquake. At present, the prices of "handheld" terminals keep dropping, but they provide more and more functions. Normally, they have the functions of text reading, video display, dictionary, game, note, etc. "Handheld" terminals are of small size and easy to carry, so they remove the constraints of time and place on learning and widen the space for physically disabled children's learning. Moreover, they can easily motivate physically disabled children in learning. Among existing activities of their utilization, teachers realize the interaction with students by means of "handheld" terminals, guide physically disabled children to visit the online knowledge system and use "handheld" terminals for reading and writing, which have achieved obvious effects. However, "mobile learning" based on "handheld" terminals may easily increase physically disabled children's interest in learning, but still easily make them addicted to it. Thus, a suitable model of supervision must be established in practice.

With regard to "software", experience in the existing cases should be learned from how "homeschoolers" make use of open resources on the internet successfully. According to statistics, America had 1.7 million homeschooled children by using online resources in 2007. (Jackie Burrell: 2007) In the past 10 years, more and more "homeschoolers" appeared in China thanks to the spread and accessibility of internet. Some content aggregator developed for learners at different ages gave much help to them, and greatly improved the efficiency of "homeschoolers" in the utilization of online information resources in a focused manner.

"Applicable" software resources refer to the information resources suitable for the cognitive characteristics of physically disabled children in the earthquake, and should be developed in the following principles: 1. Give prominence to adaptability. They should satisfy the actual needs of physically disabled children in the earthquake. 2. Underscore systematicness. They should follow the logics of knowledge and the cognitive development law of physically disabled children and make physically disabled children ready for future life. 3. Pursue openness. Learning resources should be open to schools, society and families and conveniently utilized by physically disabled children in the earthquake, and dynamically adjust to the characteristics of physically disabled children's learning, different fields, levels and environments of learning.

\section{References}

Burrell, J. (2007). Over One Million U.S. Kids Home-schooled. Retrieved from http://www.azcentral.com/families/articles/0517homeschool18.html

He, C. Q. (2008). Guide for Rehabilitation Treatment of Injured People in Earthquake. Sichuan Medical Journal Press.

Hua, D., \& Shen, W. W. (2011). Analysis on Demand of Disabled Students Caused by 5.12 Earthquake. Theory Research Press.

Luo, J. H., \& Deng, X. H. (2010). Thinking of Research on E-learning Supporting Strategy of Disabled Students Caused by Earthquake. Tribune of Education Culture Press.

Stoney, S., \& Oliver, R. (1998). Interactive Multimedia for Adult Learners: Can Learning Be Fun? Journal of Interactive Learning Research Press.

Zheng, Q. (2010). Online Resources for Special Education: Status Quo, Problems and Development Strategies. Distance Education in China Press.

Zhou, H. Y., \& Chen, L. (2009). Application Facilitates Fairness: Progress in Research on Information and Technology for Special Education. China Audiovisual Education Press. 